\title{
Case Report \\ Pancreatic Hydatid Cyst Causing Acute Pancreatitis: A Case Report and Literature Review
}

\author{
Bayan Alsaid (D), ${ }^{1,2}$ Maryam Alhimyar $\left(D,{ }^{3}\right.$ and Fadi Rayya ${ }^{1}$ \\ ${ }^{1}$ Department of General Surgery, Al-Assad University Hospital, Faculty of Medicine, Damascus, Syria \\ ${ }^{2}$ Laboratory of Anatomy, Faculty of Medicine, University of Damascus, Damascus, Syria \\ ${ }^{3}$ Faculty of Medicine, Damascus University, Damascus, Syria
}

Correspondence should be addressed to Bayan Alsaid; drbayan@gmail.com

Received 29 November 2017; Accepted 12 February 2018; Published 5 March 2018

Academic Editor: Tahsin Colak

Copyright (C) 2018 Bayan Alsaid et al. This is an open access article distributed under the Creative Commons Attribution License, which permits unrestricted use, distribution, and reproduction in any medium, provided the original work is properly cited.

Hydatidosis is a public health problem in endemic countries. Hydatid cysts are located usually in the liver and the lungs. Primary pancreatic hydatid cyst is in unusual location and rarely causes acute pancreatitis. In this paper, we report a case of a 34-year-old man who admitted with recurrent acute pancreatitis. Following the preoperation investigations, the primary impression was a pancreatic pseudocyst. During surgery, a primary hydatid cyst was detected in the pancreas measuring $35 \times 20 \times 15 \mathrm{~cm}$. The treatment consisted of evacuation and external draining of the cyst. In addition, we summarized 14 cases of primary hydatid cyst of the pancreas associated with acute pancreatitis reported in the literature.

\section{Introduction}

Echinococcosis, hydatid disease, and hydatidosis are alternative names of a zoonotic parasitic disease caused by the tapeworm Echinococcus. It is endemic in Mediterranean countries, the Middle East, South America, and the Indian subcontinent [1-3]. Four types of Echinococcus lead to infection in humans; Echinococcus granulosus is the most common parasite causing cystic echinococcosis with larval stage that represents more than $95 \%$ of cases [4]. It can infest various organs, and the invasion to the liver and lungs accounts for 90\% [5]. Other involved sites are the muscles, bones, kidneys, brain, spleen, and pancreas. Pancreatic localization is a rare situation of hydatidosis representing $0.2 \%$ of cases [6].

Acute pancreatitis is commonly associated with alcohol intake or disorders of the pancreaticobiliary tracts [7]. Acute pancreatitis has rarely been reported due to a hydatid cyst of the pancreas [8]. Only 14 cases were reported in literature.

We report a case of hydatid cyst diagnosed after acute pancreatitis episode, and we reviewed and summed the data from other reported cases of hydatid cyst manifested as acute pancreatitis in the English and French literature.

\section{Case Presentation}

A 34-year-old man was admitted to the Surgery Department in our centre in July 2016 with diffuse abdominal pain, dyspnea, general fatigue, and weakness. In his medical history, he had been admitted to another centre two months ago for an episode of acute pancreatitis.

Abdominal ultrasonography revealed a heterogeneous area of $5 \mathrm{~cm}$ in size in the body of the pancreas, peripancreatic fluid, gallstones with thickness in the gallbladder wall, and multiple cysts in the left kidney. Abdominal computed tomography (CT) showed heterogeneous collection of fluid with a thick wall of $12 \times 4 \mathrm{~cm}$ in size along the body of the pancreas and left colic angle (often an abscess or a pseudocyst) with infiltration of adipose tissue around it and mild thickness at the wall of the colon. A simple renal cyst was also reported in the left kidney (Figure 1).

Laboratory investigations were within normal levels except an elevation in C-reactive protein value $(18.1 \mathrm{mg} / \mathrm{dl})$ and amylase (765 U/L). The hepatic tests were within the normal range (total bilirubin (TB) was $0.64 \mathrm{mg} / \mathrm{dl}$, alanine aminotransferase (ALT) was $20 \mathrm{IU} / \mathrm{L}$, and aspartate transaminase (AST) was $19 \mathrm{IU} / \mathrm{L}$ ). The patient was treated as an episode of acute pancreatitis. 


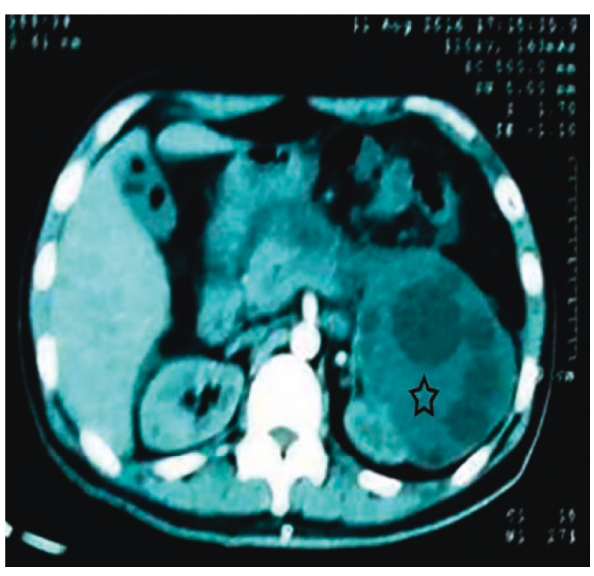

(a)

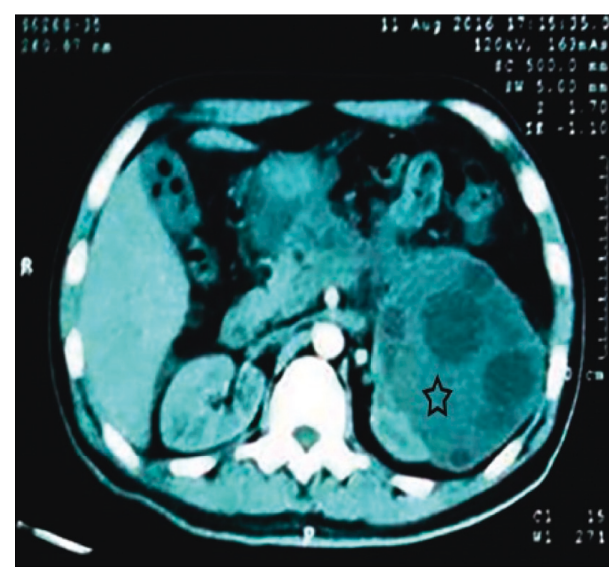

(b)

Figure 1: Computed tomography revealing a cystic lesion extending between the body of the pancreas and left kidney (black stars).

Other investigations were performed; upper gastrointestinal endoscopy (UGI endoscopy) demonstrated an esophagitis (grade A) at the lower esophagus, incompetence of the lower esophageal sphincter (LES), diffuse congestion of the mucous membrane of the stomach, and aphthous ulcer at the fundus of the stomach. Lower GI endoscopy was normal until the terminal ileum.

A month later, the CT scan for thorax and abdomen data were similar to the previous finding, and the pancreatic cyst measuring $13.5 \times 7 \mathrm{~cm}$ stretched down through the peritoneal cavity in front of the mesenteric vessels.

The laboratory values were normal, and a primary diagnosis of pancreatic pseudocyst was probable, and the decision of surgical intervention was decided.

Intraoperatively, an extreme oedema in the pylorus, the transverse mesocolon, the head and body of the pancreas, and the hepatoduodenal ligament was found. A cholecystitis required cholecystectomy. After entering the lesser sac, a large mass of $35 \times 20 \times 15 \mathrm{~cm}$ in size was found, located in the space between the tail of the pancreas, spleen, left colic angle, left kidney, stomach, and diaphragm. The mass was hard to dissect from the neighboring structures. In puncture, a clear pure liquid was aspirated proposing the existence of a hydatid cyst. Cyst fenestration was performed, and multiple daughter cysts were evacuated; the endocyst membrane was removed (Figure 2). A Foley catheter was placed in the residual cavity. The simple renal cyst needs no intervention according to the urologist. The final diagnosis was pancreatic hydatid cyst.

The patient had another episode of acute edematous pancreatitis after a month of surgery, and the amylase level was over $1000 \mathrm{U} / \mathrm{L}$. The development of local retroperitoneal abscess required puncture and drainage by CT; the patient also developed a deep venous thrombosis and was treated by anticoagulants.

During 18 months of follow-up, the patient was well with no episodes of recurrence or other complications.

\section{Literature Review}

Besides our case, 14 cases of a pancreatic hydatid cyst with acute pancreatitis were reported. Three of them are available with abstract and one is not accessible. The ratio of women to men was $3 / 10$. The mean age of the patients was 30.2 years. The location was solitary in the pancreas in 10 patients. The cyst was found in the body (7.1\%), tail (28.5\%), body and tail $(21.4 \%)$, or head $(28.5 \%)$ (Table 1$)$.

On clinical examination, no specific complaints or signs were found to distinguish hydatid cyst from other etiology of acute pancreatitis so that the final diagnosis was made preoperatively in 4 cases by ultrasonography or computed tomography. In our case, the final diagnosis was made intraoperatively.

Laboratory investigations varied between cases, and they were not available in all cases. The average of white blood cells was $17,943 / \mathrm{mm}^{3}$, and the amylase median was $1718 \mathrm{U} / \mathrm{L}$.

Surgical procedures that have been carried out varied according to every situation; for example, left pancreatectomy with splenectomy was performed in 5 cases. Only 2 patients were treated with albendazole before surgery.

After surgery, there were some complications such as external pancreatic fistula $(n=1)$, complex pancreatic fistula (an external and enterocutaneous fistula between the transverse colon and the skin surface), and portal vein thrombosis $(n=1)$. Fistulae were treated with parenteral nutrition, antibiotic therapy (ampicillin), and adequate local treatment.

The mean follow-up was 25 months without recurrence or other complications (missing value $=6$ ) $($ Table 2 ).

\section{Discussion}

Hydatid cysts can localize virtually in any organ and structure of the body. The highest rate of cysts location exists in the liver and the lungs, which assess to $70 \%$ and $20 \%$ of patients, respectively. Other organs present in a small proportion of patients [21, 22]. It is rarely detected in the pancreas.

According to a previous review in 2012 [17], the cyst is single in the pancreas in $90 \%$ of the cases. Moreover, $50 \%$ of the cysts can be located in the head, $24-34 \%$ in the body, and $16-19 \%$ in the tail.

The clinical manifestations of cystic echinococcosis (CE) depend on the size of the cyst, site, and potential complications 


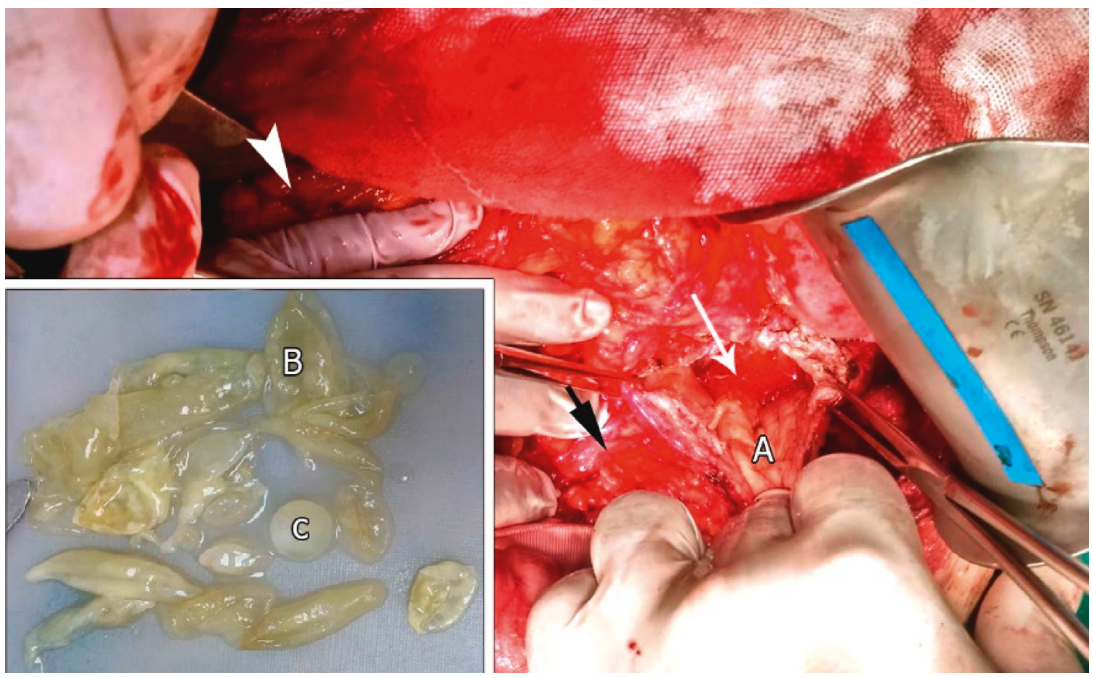

Figure 2: Intraoperative aspect. Pancreas (black arrow), opened cavity in the pancreas (white arrow), and stomach (arrowhead). A: cyst wall; B: endocystic membrane; C: daughter cyst.

TABLE 1: Summarized results of the recent review of hydatid acute pancreatitis cases.

\begin{tabular}{lc}
\hline Characteristic & Case number $(\%)$ \\
\hline Age (years) & \\
Median (30.2) & $14(100)$ \\
Range (18-51) & \\
Sex & $3(21.4)$ \\
Female & $10(71.4)$ \\
Male & $11(78.5)$ \\
Location & $1(7.1)$ \\
Solitarily in the pancreas & $1(7.1)$ \\
Liver & $1(7.1)$ \\
Kidney & $4(28.5)$ \\
Liver and left kidney & $1(7.1)$ \\
Location in the pancreas & $4(28.5)$ \\
Head & $3(21.4)$ \\
Body & \\
Tail & $7(50)$ \\
Body+ tail & \\
Size (cm) & \\
Median (7.5) & \\
Range (3.5-17) & \\
Lab investigations & \\
Total bilirubin (mg/l) & \\
$\quad$ Median (3.04) & \\
$\quad$ Range (0.4-5.9) & \\
Direct bilirubin (mg/l) & \\
$\quad$ Median (1.34) & \\
$\quad$ Range (0.3-3) & \\
Positive hydatid serology (ELISA) & \\
White blood cells (WBCs)/mm ${ }^{3}$ & \\
$\quad$ Median (17,943) & \\
$\quad$ Range (11,800-24,500) & \\
Amylase (U/L) & \\
$\quad$ Median (1718) & \\
$\quad$ Range (400-4985) & \\
Final diagnosis & \\
Preoperative & \\
Intraoperative & \\
\hline
\end{tabular}

such as rupture, compression on adjacent tissue or organs, infections, and intestinal or biliary fistula [23].

Hepatic hydatid cysts rupture into the biliary tree in $5-17 \%$ of the cases [24]. This complication is rarely associated with acute pancreatitis $[25,26]$. Hepatic hydatid cysts can also compress the biliary tract [27]. In accordance with that, we can say that the pancreatic hydatid cysts may compress Wirsung's duct or rupture into it, which produces acute pancreatitis.

Diagnosis of cystic hydatidosis is based on imaging. Ultrasonography allows classification of the cysts, as the WHO classification tabulates cysts in 3 groups: the first one is active and includes CE1, which appears as unilocular anechoic cystic lesion with double-line sign, and CE2, which is a multiseptated "rosette-like" "honeycomb" cyst; the second one is transitional and contains CE3a cyst with detached membranes (water-lily sign) and CE3b cyst with daughter cysts in the solid matrix; and finally, the third group is inactive and has CE4 and CE5 cysts with heterogeneous hypoechoic/hyperechoic contents and no daughter cysts and solid plus calcified wall [28].

CT scan demonstrates the features of hydatid cysts better than US. CT scan can identify the number, size, shape, margins, anatomic location, and calcification. Furthermore, the abdominal CT scan may be used to evaluate complications like rupture into the main pancreatic duct. It also assesses the lesions during therapy [16]. Magnetic resonance imaging (MRI) has a role in detecting the characters of the cysts and complications better than CT; however, MRI is usually not desired because of its cost [21].

The management of the cystic echinococcosis (CE) includes surgery, percutaneous treatment, antiparasitic drug therapy, and observation [29]. Surgery is the classic approach to treat $\mathrm{CE}$, and it is appropriate for complicated cysts and in cases for which percutaneous treatment is not available [29]. Evacuation of the cyst and defacement of the residual cavity are the aims of the surgical therapy [30]. 
TABLE 2: Literature review of hydatid acute pancreatitis cases.

\begin{tabular}{|c|c|c|c|c|c|c|}
\hline Case number & Source & Year & $\begin{array}{l}\text { Type of the } \\
\text { pancreatitis }\end{array}$ & Pathogenesis & Surgical treatment & $\begin{array}{c}\text { Follow-up } \\
\text { (months) }\end{array}$ \\
\hline 1 & Augustin et al. [9] & 1984 & - & Opening & Distal pancreatectomy + splenectomy & - \\
\hline 2 & Papadimitriou [10] & 1987 & Edematous & Opening & Cyst fenestration & 12 \\
\hline 3 & Lo Monte et al. [11] & 1998 & - & Compression & Cyst fenestration & - \\
\hline 4 & Ozmen et al. [12] & 2005 & Necrotizing & Compression & Cyst fenestration + splenectomy & 4 \\
\hline 5 & Pouget et al. [13] & 2009 & - & - & Distal pancreatectomy + splenectomy & - \\
\hline 6 & Chammakhi-Jemli et al. [14] & 2010 & Necrotizing & - & Distal pancreatectomy + splenectomy & - \\
\hline 7 & Karakas et al. [3] & 2010 & Edematous & Opening & Distal pancreatectomy & 4 \\
\hline 8 & Diop et al. [15] & 2010 & Edematous & Opening & Distal pancreatectomy & 48 \\
\hline 9 & Suryawanshi et al. [16] & 2011 & Edematous & Compression & Laparoscopic evacuation & 3 \\
\hline 10 & Makni et al. [17] & 2012 & Edematous & Opening & Distal pancreatectomy + splenectomy & 8 \\
\hline 11 & Birlutiu and Birlutiu [18] & 2015 & Necrotizing & - & Operculectomy & 98.5 \\
\hline 13 & Mohamed et al. [19] & 2015 & Atrophy & - & Distal pancreatectomy + splenectomy & - \\
\hline 14 & Mattous and Belabbes [20] & 2015 & - & - & Evacuation and external drainage & - \\
\hline 15 & Our case & 2017 & Edematous & Compression & Evacuation and external drainage & 18 \\
\hline
\end{tabular}

PAIR (puncture, aspiration, injection of a scolicidal agent, and reaspiration) is one technique of percutaneous treatment used as a therapeutic and diagnostic option that counts as an effective replacement to surgery with lower rates of recurrence and mortality [28]. Medical therapy is useful when it is combined with/to surgery and percutaneous therapy. Drug treatment before and after the procedure reduces the risk of recurrence. The first medication to be used is mebendazole and then there were albendazole and praziquantel. Albendazole is the most effective [11].

\section{Conclusion}

Despite pancreatic hydatid cyst being rare, it may be treated as a reason to acute pancreatitis. Hydatid cysts should be counted as a significant differential diagnosis for cystic lesions of the pancreas and other organs, especially in endemic regions. Clinicians must know about complications of hydatid cyst in its uncommon locations.

\section{Conflicts of Interest}

The authors declare that there are no conflicts of interest regarding the publication of this paper.

\section{References}

[1] N. Altinors, E. Senveli, T. Dönmez, M. Bavbek, Z. Kars, and M. Sanli, "Management of problematic intracranial hydatid cysts," Infection, vol. 23, no. 5, pp. 283-287, 1995.

[2] M. C. Goel, M. R. Agarwal, and A. Misra, "Percutaneous drainage of renal hydatid cyst: early results and follow-up," British Journal of Urology, vol. 75, no. 6, pp. 724-728, 1995.

[3] E. Karakas, Y. Tuna, O. Basar, and S. Koklu, "Primary pancreatic hydatid disease associated with acute pancreatitis," Hepatobiliary \& Pancreatic Diseases International, vol. 9, no. 4, pp. 441-442, 2010.

[4] C. M. Budke, P. Deplazes, and P. R. Torgerson, "Global socioeconomic impact of cystic echinococcosis," Emerging Infectious Diseases, vol. 12, no. 2, pp. 296-303, 2006.
[5] Z. S. Amr, S. Jitawi, and H. Annab, "Hydatidosis in Jordan: an epidemiological study of 306 cases," Annals of Tropical Medicine \& Parasitology, vol. 88, no. 6, pp. 623-627, 1994.

[6] F. Abi, F. el Fares, D. Khaiz, and A. Bouzidi, "Unusual localizations of hydatid cysts. Apropos of 40 cases," Journal de Chirurgie, vol. 126, no. 5, pp. 307-312, 1989.

[7] P. A. Testoni, "Aetiologies of recurrent acute pancreatitis: acute or chronic relapsing disease?," JOP, vol. 2, no. 6, pp. 357-367, 2001.

[8] A. Hammad and B. Mentouri, "Acute pancreatitis in Algeria. Report of 221 Cases," American Journal of Surgery, vol. 149, no. 6, pp. 709-711, 1985.

[9] N. Augustin, G. Gamstätter, M. Neher, T. Schreyer, and S. Störkel, "Echinococcus cysticus of the pancreas in the clinical picture of acute pancreatitis," Der Chirurg, vol. 55, no. 10, pp. 661-664, 1984.

[10] J. Papadimitriou, "Pancreatic abscess due to infected hydatid disease," Surgery, vol. 102, no. 5, pp. 880-882, 1987.

[11] A. Lo Monte, C. Maione, and N. Napoli, "Renal hydatidosis. Discussion of a clinical case complicated by post acute pancreatitic cyst," Minerva Chirurgica, vol. 53, no. 7-8, pp. 659-662, 1998.

[12] M. M. Ozmen, M. Moran, M. Karakahya, and F. Coskun, "Recurrent acute pancreatitis due to a hydatid cyst of the pancreatic head: a case report and review of the literature," JOP, vol. 6, no. 4, pp. 354-358, 2005.

[13] Y. Pouget, S. Mucci, D. O’Toole, E. Lermite, C. Aubé, and A. Hamy, "Recurrent acute pancreatitis revealing a hydatid cyst of the pancreas," La Revue de Médecine Interne, vol. 30, no. 4, pp. 358-360, 2009.

[14] C. Chammakhi-Jemli, S. Mekaouer, A. Miaoui et al., "Hydatid cyst of the pancreas presenting with acute pancreatitis," Journal de Radiologie, vol. 91, no. 7-8, pp. 797-799, 2010.

[15] S. P. Diop, R. Costi, A. Le Bian, A. Carloni, B. Meduri, and C. Smadja, "Acute pancreatitis associated with a pancreatic hydatid cyst: understanding the mechanism by EUS," Gastrointestinal Endoscopy, vol. 72, no. 6, pp. 1312-1314, 2010.

[16] P. Suryawanshi, A. Q. Khan, and S. Jatal, "Primary hydatid cyst of pancreas with acute pancreatitis," International Journal of Surgery Case Reports, vol. 2, no. 6, pp. 122-124, 2011.

[17] A. Makni, M. Jouini, M. Kacem, and Z. Safta, "Acute pancreatitis due to pancreatic hydatid cyst: a case report and review of the literature," World Journal of Emergency Surgery, vol. 7, no. 1, p. 7, 2012.

[18] V. Birlutiu and R. M. Birlutiu, "The management of abdominal hydatidosis after the rupture of a pancreatic hydatid 
cyst: a case report," Journal of Medical Case Reports, vol. 9, p. 27, 2015.

[19] H. Mohamed, S. Azza, A. Chrif, S. Karim, and C. Adnen, "Hydatid cyst of the pancreas revealed by acute pancreatitis: report of a case," Pan African Medical Journal, vol. 22, p. 166, 2015.

[20] M. Mattous and S. Belabbes, "Acute pancreatitis revealing a hydatid cyst of the pancreas," Pan African Medical Journal, vol. 20, p. 429, 2015.

[21] R. W. Ammann and J. Eckert, "Cestodes. Echinococcus," Gastroenterology Clinics of North America, vol. 25, no. 3, pp. 655-689, 1996.

[22] J. Eckert, B. Gotstein, D. Heath, and F. J. Liu, "Prevention of echinococcosis in humans and safety precautions," in WHO/OIE Manual on Echinococcosis in Humans and Animals, J. Eckert, M. A. Gemmell, F. X. Meslin, and Z. Pawlowski, Eds., p. 96, Office International des E'pizooties, Paris, France, 2001.

[23] N. I. Agudelo Higuita, E. Brunetti, and C. McCloskey, "Cystic echinococcosis," Journal of Clinical Microbiology, vol. 54, no. 3, pp. 518-523, 2016.

[24] F. Saez-Royuela, L. Yuguero, A. López-Morante, J. C. PérezÁlvarez, J. L. Martín-Lorente, and C. Ojeda, “Acute pancreatitis caused by hydatid membranes in the biliary tract: treatment with endoscopic sphincterotomy," Gastrointestinal Endoscopy, vol. 49, no. 6, pp. 793-796, 1999.

[25] S. Mestiri, M. Hadj Salah, R. Laarif, and M. Kehila, "Hepatic hydatid cyst opening into the bile ducts and acute pancreatitis: etiopathogenic problems apropos of 3 cases," Médecine \& Chirurgie Digestives, vol. 11, no. 3, pp. 197-199, 1982.

[26] A. Aydin, G. Ersöz, O. Tekesin, and A. Mentes, "Hydatid acute pancreatitis: a rare complication of hydatid liver disease. Report of two cases," European Journal of Gastroenterology \& Hepatology, vol. 9, no. 2, pp. 211-214, 1997.

[27] M. Miyamoto, M. Oka, T. Izumiya et al., "Nonparasitic solitary giant hepatic cyst causing obstructive jaundice was successfully treated with monoethanolamine oleate," Internal Medicine, vol. 45, no. 9, pp. 621-625, 2006.

[28] World Health Organization, PAIR: Puncture, Aspiration, Injection, Re-Aspiration-An Option for the Treatment of Cystic Echinococcosis, World Health Organization, Geneva, Switzerland, 2001.

[29] E. Brunetti, P. Kern, and D. A. Vuitton, "Expert consensus for the diagnosis and treatment of cystic and alveolar echinococcosis in humans," Acta Tropica, vol. 114, no. 1, pp. 1-16, 2010.

[30] A. A. Balik, "Surgical treatment of hydatid disease of the liver: review of 304 cases," Archives of Surgery, vol. 134, no. 2, pp. 166-169, 1999. 


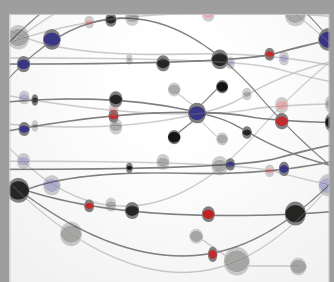

The Scientific World Journal
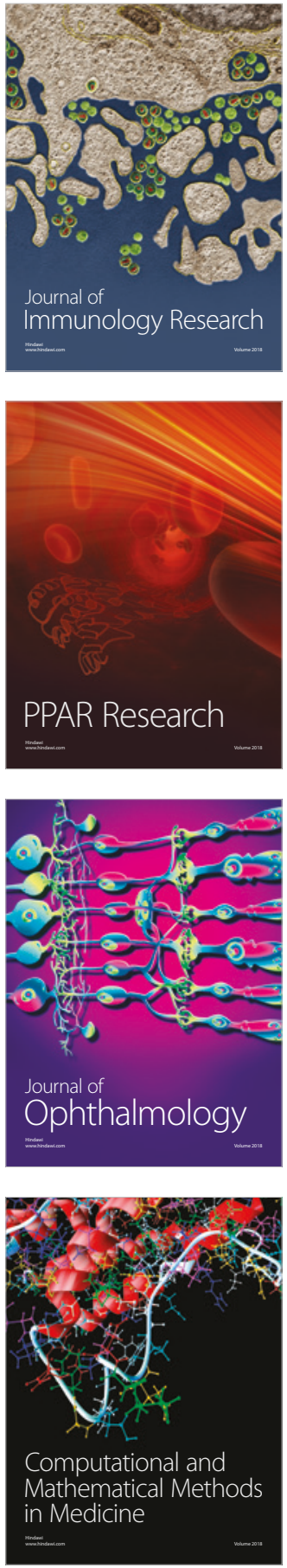

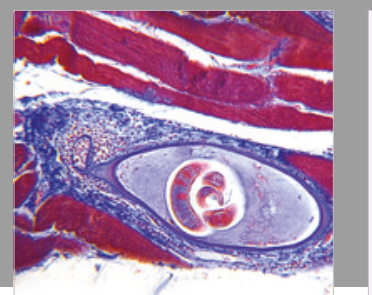

Gastroenterology Research and Practice

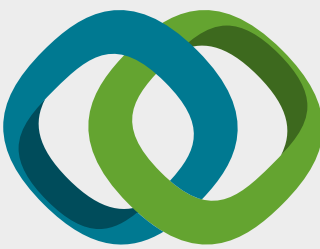

\section{Hindawi}

Submit your manuscripts at

www.hindawi.com
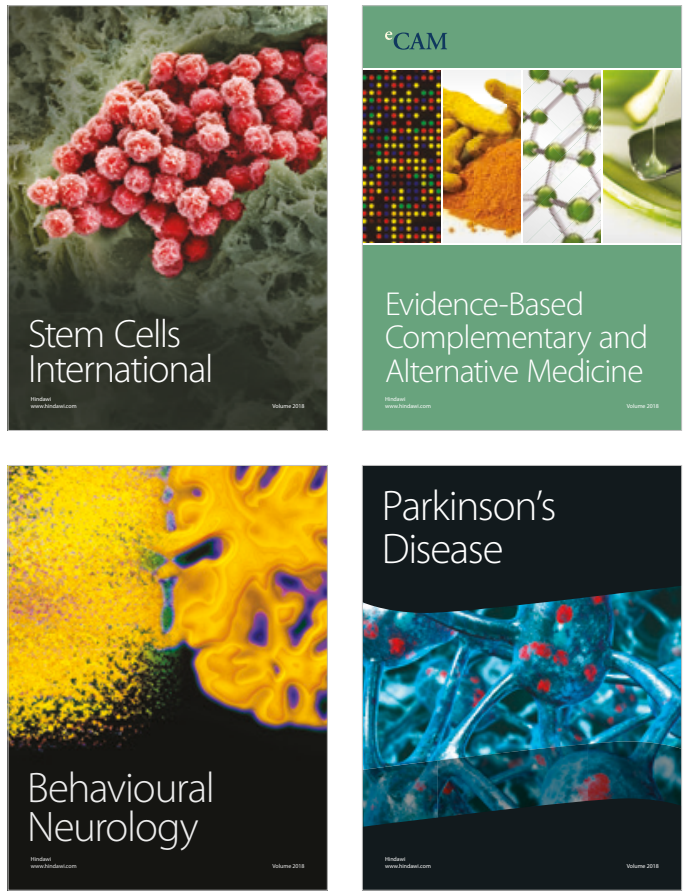

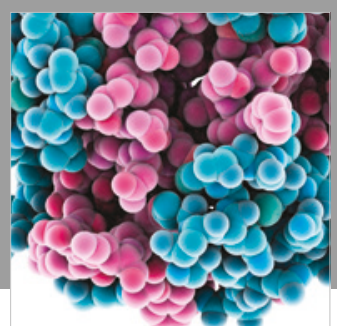

ournal of

Diabetes Research

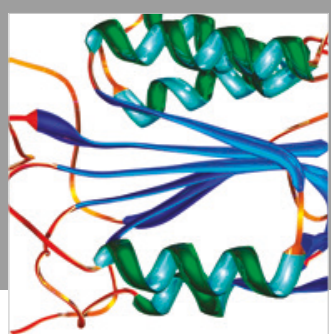

Disease Markers
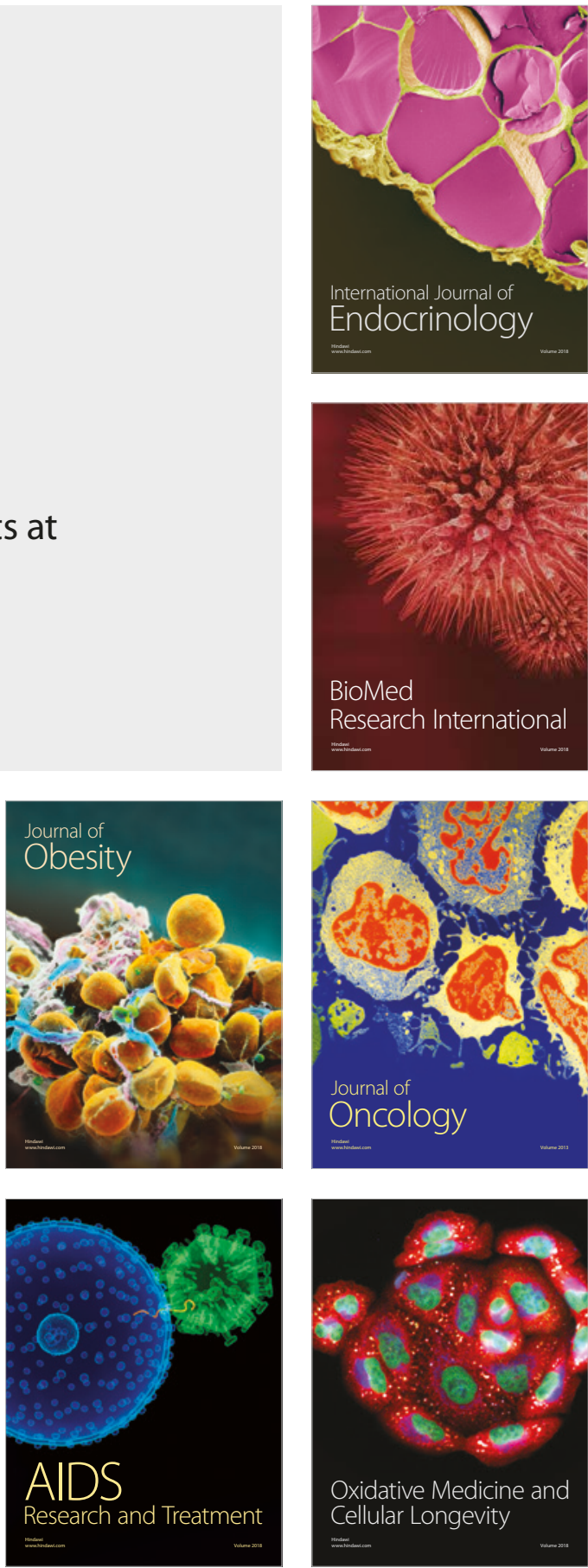